\title{
Efeito do extrato aquoso de Cordyline Dracaenóides Kunth na cicatrização de lesões cutâneas
}

\author{
Effect of aqueous extract of Cordyline Dracaenóides Kunth on wound healing \\ of skin lesions \\ Ivo Ilvan Kerppers ${ }^{1}$ (D), Flávio Klinpovous Kerppers² (D), Kesia Maria Mangoni Gonçalves dos Santos ${ }^{2}$ (D), \\ Maria Elvira Ribeiro Cordeiro² (D), Mario César da Silva Pereira ${ }^{1}$ (D)
}

\begin{abstract}
RESUMO
Método de estudo: trata-se de um estudo experimental, randomizado. Introdução: O processo de cicatrização é um conjunto dinâmico de alterações teciduais importantes que envolve inflamação e quimiotaxia. A Cordyline Dracaenóides Kunth, conhecida popularmente como Uvarana, é uma planta que contribui com o processo de cicatrização. Objetivo: Nesse contexto, o objetivo desse trabalho foi verificar os efeitos do extrato aquoso de Uvarana no processo cicatricial. Método: A amostra foi composta por 42 ratos da raça Rattus norvegicus, Wistar, divididos em quatro grupos experimentais: Grupo Controle Negativo, Grupo Controle Positivo, Grupo Uvarana e Grupo Fármaco, subdivididos em 3 e 7 dias. Os animais foram anestesiados com $80 \mathrm{mg} / \mathrm{kg}$ de Ketamina e $15 \mathrm{mg} / \mathrm{kg}$ de Xilazina e, em seguida, foram posicionados em decúbito ventral sobre uma prancha cirúrgica. Após isso, foi realizada a tricotomia da região dorsal e com uma lâmina de bisturi, foi feita uma incisão de $10 \mathrm{~mm}$. Após a incisão, foi realizado o fechamento da ferida com fio de nylon número 5.0. Resultados: Observou-se que, no grupo em que foi aplicado o extrato aquoso de Uvarana, houve uma regeneração da epiderme com presença de crosta, o tecido dérmico apresentou células inflamatórias, a hipoderme teve intensa inflamação, a epiderme ficou mais espessa ao sétimo dia e a derme apresentou células regenerativas de colágeno e fechamento da cicatriz. Conclusão: Com base nesse estudo, pode-se concluir que o extrato aquoso de Uvarana é um método bastante eficaz no tratamento de lesões cutâneas e tem a capacidade de acelerar o processo de cicatrização.
\end{abstract}

Palavras-Chave: Cicatrização; Colágeno; Planta.

\begin{abstract}
Method of study: This is an experimental, randomized study. Introduction: The healing process is a dynamic set of important tissue changes involving inflammation and chemotaxis. Cordyline Dracaenoides Kunth, popularly known as Uvarana, is a plant that contributes to the healing process. Objective: In this context, this work aimed to verify the effects of the aqueous extract of Uvarana on the healing process. Method: The sample consisted of 42 Rattus norvegicus, Wistar rats divided into four experimental groups: Negative Control Group, Positive Control Group, Uvarana Group, and Fármaco Group, subdivided in 3 and 7 days. The animals were anesthetized with $80 \mathrm{mg} / \mathrm{kg}$ Ketamine and $15 \mathrm{mg} / \mathrm{kg}$ Xylazine and then placed in a ventral decubitus position on a surgical plank, after which a dorsal region tricotomy was performed and with a scalpel blade was made a $10 \mathrm{~mm}$ incision. After the incision, wound closure was performed with nylon thread number 5.0. Results: It was observed that in the group in which the aqueous extract of Uvarana was applied, there was a regeneration of the epidermis with presence of crust, the dermal tissue presented inflammatory cells, the hypodermis had intense inflammation, the epidermis became thicker on the seventh day and the dermis presented regenerative collagen cells and scar closure. Conclusion: Based on this study, it can be concluded that the aqueous extract of Uvarana is a very effective method in the treatment of cutaneous lesions and has the capacity to accelerate the healing process.
\end{abstract}

Keywords: Wound Healing; Collagen; Plant.

1. Professor. Laboratório de Neuroanatomia e Neurofisiologia, Universidade Estadual do Centro Oeste (UNICENTRO), Guarapuava (PR), Brasil.

2. Acadêmico do curso de Farmácia. UNICENTRO, Guarapuava (PR), Brasil.

$\bowtie$ Ivo Ilvan kerppers. Rua Simeão Varela de Sá, 03 - Vila Carli. CEP: 85040-080. Guarapuava (PR), Brasil.

ikerppers@hotmail.com | Recebido: 14/09/2018 | Aprovado: 02/09/2019 


\section{INTRODUÇÃO}

$A_{c}^{s}$ tentativas do homem de intervir no processo de cicatrização de feridas remontam à Antiguidade, quando foi reconhecida a importância de protegê-las para evitar complicações. Os portadores de feridas desenvolvem sequelas com frequência, com consequências sociais intensas, podendo ocorrer perda de membros e funções, afastando a pessoa do trabalho e, por vezes, obrigando-a a aposentadoria precoce por invalidez ${ }^{1}$.

A pele e seus anexos constituem o maior órgão do corpo humano e representa a barreira física com o meio que o cerca. A pele é formada pela epiderme, tecido epitelial pavimentoso estratificado queratinizada e a derme constituída de tecido conjuntivo. Quando estes tecidos são lesionados, o organismo reage para reparação do mesmo através do processo de cicatrização².

A cicatrização constitui um conjunto dinâmico de alterações teciduais importantes na manutenção da integridade do organismo, envolve inflamação, quimiotaxia, proliferação celular, diferenciação e remodelação ${ }^{3}$.

As feridas podem ser classificadas de acordo com o tempo de reparação do tecido, em agudas e crônicas. As agudas são originadas de cirurgia ou trauma e a reparação ocorre em tempo adequado, sem complicações. As feridas crônicas não são reparadas em tempo esperado e apresentam complicações ${ }^{1}$.

A cicatrização é um dos processos mais estudados atualmente. Pesquisas têm avaliado a importância de sua estimulação na reabilitação funcional e estética do paciente. A cicatrização pode ocorrer por primeira ou segunda intenção, com estágios inflamatórios, fibroblásticos e remodelador. Ao longo do tempo, o homem sempre empregou artifícios com o intuito de aperfeiçoar o processo cicatricial através do uso de substâncias ou procedimentos ${ }^{2,4,5}$.

Formação de cicatrizes na pele é um resultado comum do processo de cicatrização de feridas. Clinicamente, cicatrizes variam muito e, normalmente, variam de linhas finas de expansivo, desfigurando o tecido em hipertrófica ou quelóide. Eles também diferem, dependendo de fatores como a extensão do trauma, sua localização no corpo, fatores genéticos, sexo e idade do paciente $e^{6,7,8}$.
No nível molecular, a formação de cicatriz é marcada pelo acúmulo de colágeno e fibronectina rico em matriz extracelular (ECM) em resposta ao aumento da atividade de fator de crescimento transformador- $\beta 1$ (TGF- $\beta 1$ ) e redução de fibroblastos na matriz extracelular ${ }^{9,10,11}$. Em cicatrizes, os feixes de fibras de colágeno são densas, paralelas, finas e orientadas para o outro ao invés de arranjado no padrão visto no tecido normal. Fibras elásticas são fragmentadas e não organizadas, e apêndices dérmicos muitas vezes em falta. Devido a estas características, as cicatrizes são menos elásticas e têm apenas cerca de $70 \%$ da resistência à tração de pele intacta ${ }^{12,13,14}$.

Desde a antiguidade, o emprego de plantas medicinais como recurso terapêutico é muito comum. O conhecimento sobre suas propriedades implica na sua utilização como terapia para diversos tipos de enfermidades ${ }^{15}$.

O estudo de Capella ${ }^{16}$, que utilizou o extrato oleoso de urucum (Bixa orellana L.) para tratamento de lesões em modelo animal, evidencia que o emprego de plantas medicinais no tratamento de feridas auxilia de forma considerável e acelera o processo cicatricial, corroborando com os achados do experimento de Faleiro ${ }^{17}$, que utilizaram o extrato glicólico de Aloe vera para tratamento de cortes realizados em ratos, apresentando resultados significativos pelo uso do fitoterápico, facilitando a cicatrização do tecido lesionado.

A Cordyline dracaenoides Kunth pertence à família Agavaceae, comumente chamada de Uvarana, única espécie neotropical do gênero, é uma planta monocotiledônea do porte de uma árvore pequena, com até $9 \mathrm{~m}$ de altura no Brasilis.

A Uvarana é perenifólia e no sul do Brasil sua floração e frutificação ocorrem respectivamente, nos períodos de outubro-novembro e dezembro-março. De utilização recorrente em vários segmentos econômicos seus vários produtos e usos, todos apresentam ainda discreta expressão econômica. As folhas podem ser utilizadas como amarrilhos nas propriedades rurais, o ápice dos ramos serve para alimentação animal e inclui também o "palmito de Uvarana"18.

A espécie Uvarana é utilizada na medicina popular em preparações anti-inflamatórias para o tratamento de reumatoides, dores nas costas e crescimento dos cabelos $^{19}$. 
O estudo de Souza ${ }^{20}$, relata que a Uvarana apresenta atividade anestésica e antiedematogênica devido a presença de esteróides, antocianinas, saponinas e concentrações de taninos em extratos hidroalcoólicos de raízes e folhas, o que é de grande valia no âmbito clínico para o tratamento de feridas.

As saponinas esteroidais são encontradas exclusivamente nas angiospermas monocotiledôneas. Esta tendência é confirmada pela presença de saponina nas famílias de monocotiledôneas do Agavaceae, Alliaceae, Asparagaceae, Dioscoreaceae, Dracaenaceae, Liliaceae e Taccaceae ${ }^{21}$.

As saponinas possuem propriedades biológicas e farmacológicas como: atividade hemolíti$\mathrm{ca}^{22,23}$, atividade anti-inflamatória ${ }^{23,24}$, atividade anti-fúngica ${ }^{19,23}$, atividade antibacteriana ${ }^{25,26}$, atividade antiparasitária27,28, atividade antitumoral e citotóxica ${ }^{28,29}$, atividade antiviral ${ }^{30}$, efeito sobre a cicatrização de feridas $^{31}$ e atividade antioxidante ${ }^{32}$.

O presente estudo teve como objetivo verificar os efeitos do extrato aquoso da Cordyline Dracaenóides Kunth no processo de cicatrização em modelo experimental.

\section{METODOLOGIA}

\section{Amostras}

Foi composta por 42 Rattus norvegicus, Wistars, pesando aproximadamente 200 gramas, separados em grupos e alocados quatro animais por gaiola com livre acesso a água e comida (ad libitum), seguindo o ciclo claro/escuro de 12 horas, com temperatura ambiente de $25 \pm 1{ }^{\circ} \mathrm{C}$. Protocolo de aprovação pelo Comitê de Ética em Uso de animais - CEUA/UNICENTRO, número 037/2014.

\section{Grupos Experimentais}

Grupo Controle Positivo: constituído por 12 animais, divididos em dois subgrupos, grupo controle positivo três dias, com eutanásia no quarto dia e grupo controle positivo sete dias, com eutanásia no oitavo dia, em ambos os grupos foi realizada a lesão tecidual, mas sem tratamento.
Grupo Extrato Uvarana: constituído por doze animais, divididos em dois subgrupos, grupo Uvarana três dias, com eutanásia no quarto dia e grupo Uvarana sete dias, com eutanásia no oitavo dia, em ambos os grupos foi realizada a lesão tecidual com aplicação sobre a ferida do extrato de Uvarana $(1 \mathrm{mg} / \mathrm{ml})$.

Grupo Fármaco: constituído por doze animais, divididos em dois subgrupos, grupo Fibrase três dias, com eutanásia no quarto dia e grupo Fibrase sete dias, com eutanásia no oitavo dia, em ambos os grupos foi realizada a lesão tecidual e aplicada sobre a ferida uma camada de pomada Fibrase.

\section{Coleta do Material}

\section{Procedimento cirúrgico}

Os animais foram anestesiados com $80 \mathrm{mg} / \mathrm{kg}$ de Ketamina e $15 \mathrm{mg} / \mathrm{kg}$ de Xilazina por via intraperitoneal. Após a verificação do estado anestésico dos animais através da compressão manual da cauda, os mesmos foram posicionados em decúbito ventral sobre uma prancha cirúrgica, e realizada a tricotomia da região dorsal do lado direito, aproximadamente de $3 \mathrm{~cm}$, em seguida foi realizada através de uma lâmina de bisturi número 3 uma incisão de $10 \mathrm{~mm}$, lesionando a epiderme, derme e a hipoderme até o aparecimento da fáscia muscular. Após a incisão, foi realizado o fechamento da ferida com fio de nylon número 5.0, em três pontos apenas, posicionando a pele de forma que não tivesse dobra ou sobreposição da mesma.

\section{Coleta do Material}

O material foi coletado nas coordenadas Latitude -24.7882547 e Longitude -51.7869108, no município de Pitanga, Paraná, entre abril e maio de 2014. A amostra não foi feita exsicata pelo fato de não se encontrar no período de florescimento, o qual acontece nos meses de março e novembro.

\section{Preparação do Extrato}

Para a preparação do extrato aquoso da Cordyline dracaenoides Kunth, a raiz foi inicialmente submetida à desidratação em estufa $\left(37^{\circ} \mathrm{C}\right)$, 
por aproximadamente 72 horas e posteriormente triturada em moinho elétrico. A etapa seguinte incidiu na preparação do extrato por decocção a partir do pó, utilizando 1 grama do pó da raiz da Uvarana diluída em 1 litro de água e fervida por 15 minutos. Após a liofilização foi diluído $1 \mathrm{mg}$ em $1 \mathrm{ml}$ de salina para a observação do efeito cicatrizante do extrato de Uvarana, e embebido em algodão sobre a solução de continuidade por 1 minuto observando que a pele permaneceu úmida com o extrato.

\section{Emulsão com Extrato de Uvarana}

O Extrato aquoso de Uvarana foi feito através da pesagem de $1 \mathrm{~g}$ de raiz moída adicionada a 1 litro de água e fervida por 10 minutos. A fervura foi filtrada em papel filtro número 3 , e o filtrado foi levado ao congelador a $-80{ }^{\circ} \mathrm{C}$ para congelamento rápido e após o congelamento foi levado para ser liofilizado, obtendo-se, assim, uma pasta densa com os constituintes da planta. Para a observação do efeito cicatrizante do extrato de Uvarana, foi realizada sobre a pele suturada a colocação de algodão embebido no extrato contendo $1 \mathrm{mg} / \mathrm{ml}$, permanecendo por 100 segundos sobre a ferida para o grupo de Uvarana e para o grupo associado LED e Uvarana.

\section{Eutanásia}

Os animais foram anestesiados com $80 \mathrm{mg} / \mathrm{kg}$ de Ketamina e $10 \mathrm{mg} / \mathrm{kg}$ de Xilazina, após verificado o estado anestésico, os mesmos receberam $30 \mathrm{mg} / \mathrm{kg}$ de Pentobarbital por via intraperitoneal.

\section{Histologia}

Após a eutanásia dos animais, a pele foi retirada através de corte e colocada em formol a $10 \%$, levada ao Laboratório de anatomia patológica e citopatologia, sem descrição dos frascos, apenas contendo números específicos para cada frasco. Sendo realizado o término do processo de inclusão em parafina, corte histológico de $2 \mathrm{mi}$ cro e coloração por hematoxilina-Eosina, foi realizada análise do tecido da porção mediana para as bordas.

\section{Método para análise de Colágenos}

Para o estudo e obtenção dos resultados, foram selecionados aleatoriamente cinco cortes histológicos da lâmina corada com $\mathrm{HE}$, correspondente a região mediana da pele. Para a verificação do colágeno, foram utilizados cinco cortes de dois micrometros de cada amostra e corada com Picrosirius, com análise em Microscópio de Luz polarizada.

\section{Análise histomorfométrica}

Após análise qualitativa, com auxílio da ferramenta Plugin "Cell Counter" do software Image ${ }^{\circledR}$ (Instituto Nacional de Saúde, EUA), os mesmos campos selecionados anteriormente foram fotografados em grande aumento (400x), através de um microscópio com câmera acoplada (2.0 M Pixel USB 2.0 com câmera acoplada software MIPro Standard versão 1.1) e realizadas as contagens dos números de células inflamatórias (PMN e MN). As células foram classificadas com base nas suas características morfológicas, como descrito a seguir (Adaptado de RAHDE, 2010; BRIZENO et al, 2016): a) Polimorfonucleares: células de núcleo segmentado e morfologia multilobulada. b) Mononucleares: células sem núcleo segmentado e morfologia unilobulada.

O somatório das células existentes nos cinco/dez campos por animal foi considerado como uma unidade amostral. Todas as análises foram realizadas de maneira cega por um único operador. Os dados foram expressos na forma de média \pm DP das unidades amostrais de cada subgrupo.

\section{Análise Estatística}

Para a análise estatística dos dados, foi utilizado o teste Kruskal-Wallis com pós teste de Dunn's, pelo software SPSS 19, considerado o nível de significância em $5 \%$, sendo estabelecido como significativo se $p<0,05$.

\section{RESULTADOS}

A Figura 1 mostra o controle positivo aos três e sete dias, apresentando, no terceiro dia, células infla- 
matórias de grau severo, intensa exsudação proteica, presença de hemorragia moderada, observa-se uma crosta sobre o tecido inflamado. Ao sétimo dia observa-se uma regeneração da epiderme com crosta na região do stratum corneum, na região da derme apresenta células polimorfonucleares (PMN's) de intensidade moderada, o colágeno apresenta-se disperso e não organizado, pouca neoformação vascular.

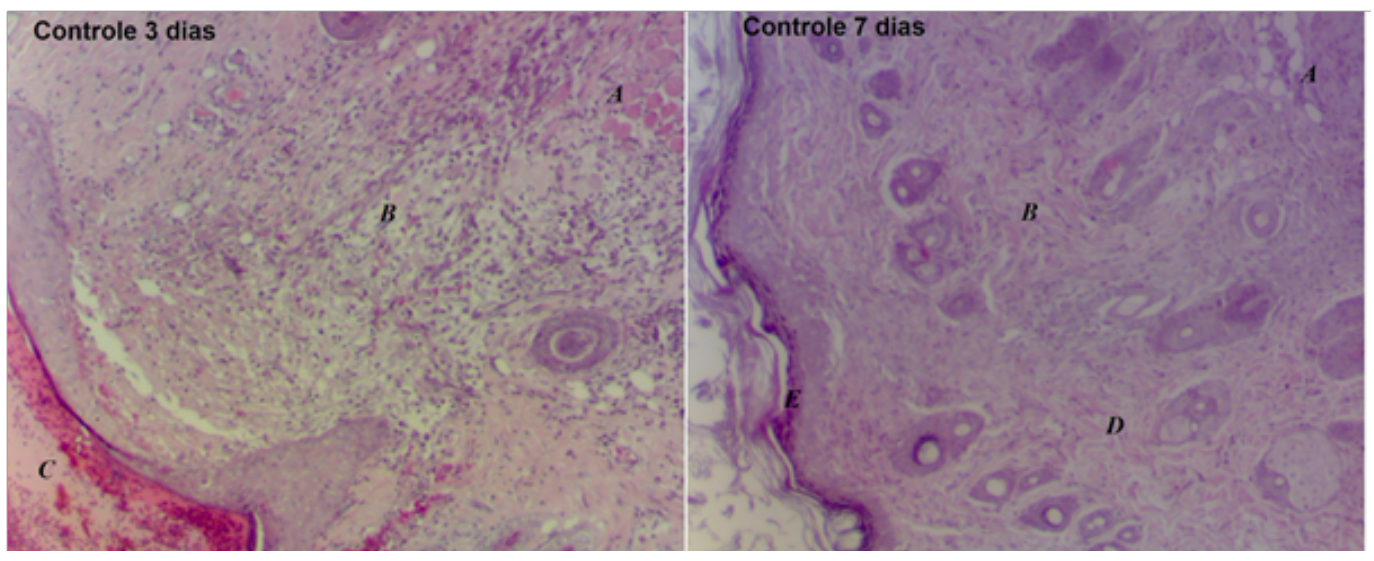

Figura 1: Lesão tecidual no grupo controle positivo (A) região da derme com presença de células inflamatórias, (B) região da derme ampla exsudação proteica e células inflamatórias, (C) crosta densa no terceiro dia. (D) região da derme no sétimo dia do grupo controle positivo apresentando células inflamatórias e $(E)$ região da epiderme com regeneração da do stratum corneum.

No terceiro dia para o grupo tratado com uso tópico de Fibrase pode-se observar que a região epidérmica apresentou uma regeneração intensa, com células fibrinolíticas tanto no stratum corneum quanto no stratum basale, pouco ou quase nenhuma região de crosta, as fibras de colágeno mostram-se desalinhada com grande presença de fibrócitos e presença de células PMN's. No mesmo grupo ao sétimo dia, nota-se que a epiderme se apresenta totalmente integrada ao tecido com presença de uma camada linear do stratum corneum. Na região da derme observam-se as fibras de colágeno organizadas e presença de fibrócitos em pequena quantidade mostrado na Figura 2 .
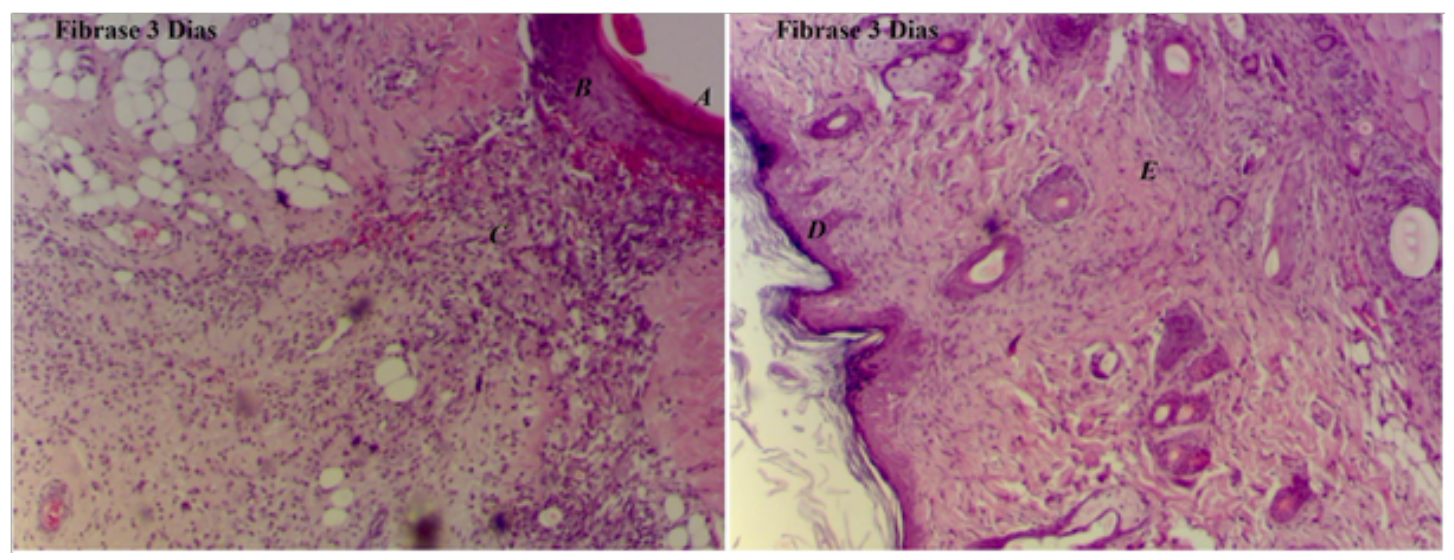

Figura 2: Grupo tratado com uso tópico de Fibrase. (A) crosta, (B) epiderme apresentando os níveis de regeneração, (C) derme com presença de células PMN, (D) epiderme ao sétimo dia íntegra e (E) derme com presença de fibrócitos e colágeno organizado semelhante ao tecido normal.

Na Figura 3 observa-se no terceiro dia para o grupo aplicado extrato de Uvarana tópico a presença de neoformação vascular de modo intenso, presença de células PMN's, exsudação protéico moderado e colágeno desorganizado. No sétimo dia, observação células de inflamação crônica (plasmócitos, linfócitos), presença de fibroblastos e fibrócitos, e neoformação vascular. 


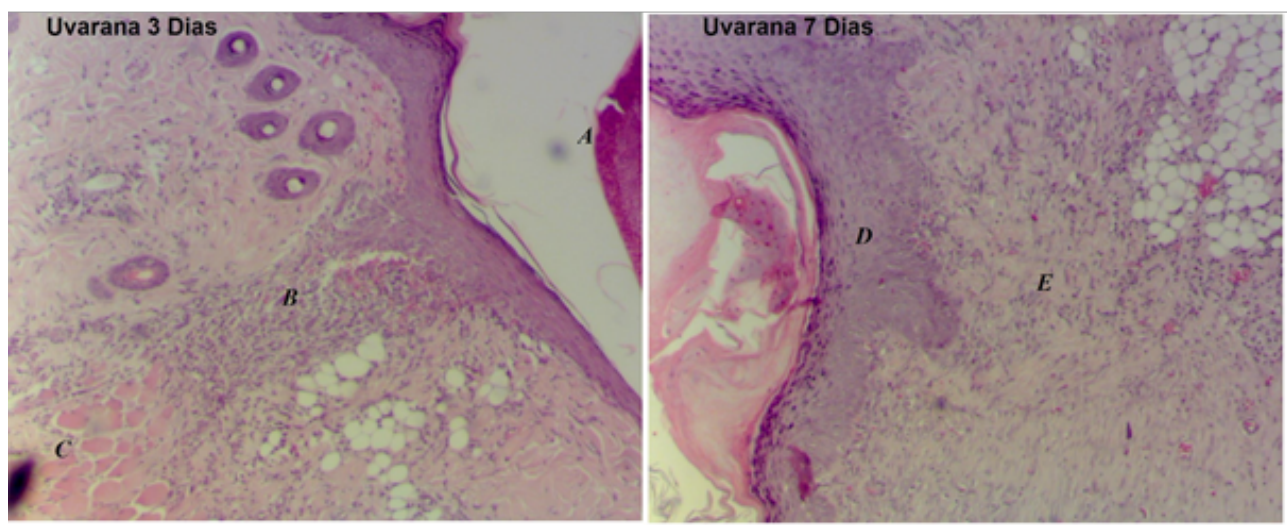

Figura 3: Grupo aplicado Extrato aquoso de Uvarana terceiro e sétimo dia. (A) Epiderme regenerada com presença de crosta, (B) tecido dérmico com presença de células inflamatórias, (C) hipoderme com intensa inflamação, (D) epiderme mais espessa ao sétimo dia e (E) derme apresentando célula regenerativa de colágeno e fechamento da cicatriz.

Na Figura 4 estão demonstrados os valores em média da área de lesão entre terceiro dia e sétimo dia. Observa-se que em relação ao grupo controle positivo no terceiro dia, os grupos tratados com o fármaco tópico e extrato de Uvarana tiveram uma redução na área lesionada demonstrando a ação e o efeito na regeneração do tecido lesionado. Observa-se que o grupo tratado com o extrato de Uvarana teve um efeito melhor na área de lesão que os demais grupos.

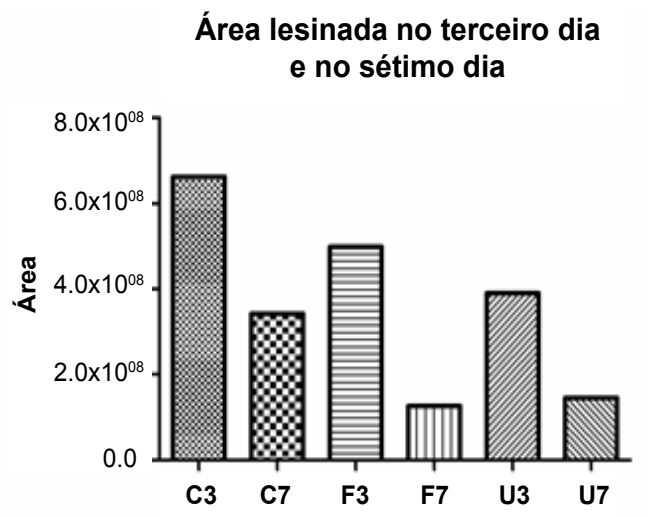

Figura 4: Diferença da área de lesão dos grupos tratados.

Na Figura 5 estão dispostos os valores médios e o desvio padrão da contagem celular para polimorfonucleares. Nota-se que ocorreu uma diminuição nos grupos estudados. O número de células encontradas foi menor no grupo aplicado o fármaco tópico e no grupo aplicado o extrato aquoso da Uvarana. No teste estatístico para amostras independentes (Chi-quadrado) foi encontrado significância entre os grupos fármaco três e sete dias com valor de $p=0.0043$ e no grupo aplicado o extrato de Uvarana entre três e sete dias com $p=0.0043$. Observou-se que ocorreu uma significância entre os grupos controle três dias e fármaco sete dias, e entre o controle três dias e o grupo aplicado extrato de Uvarana sete dias.

\section{Contagem de Polimorfonucleares}
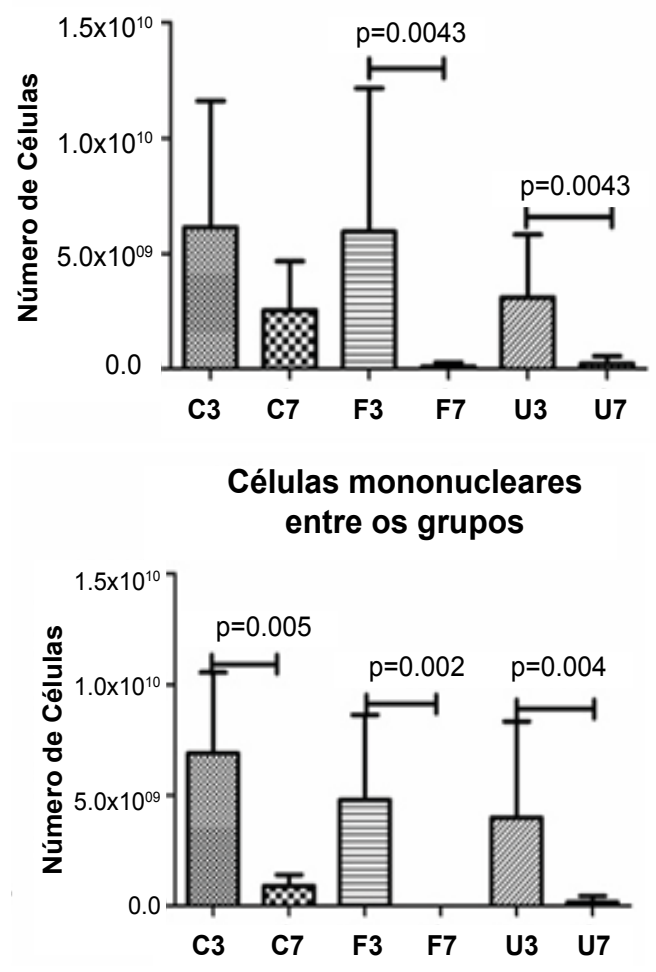

Figura 5: Presença de células PMN's e Mononucleares na área da lesão entre o terceiro dia e sétimo dia. Significância para $p<0.05$. 
A presença de neutrófilos, demonstra uma diminuição do processo cicatricial nos grupos controle, fármaco e do extrato de Uvarana. Observa-se que ocorreu uma redução completa no grupo utilizado o fármaco e semelhante ao grupo utilizado o extrato de Uvarana. Na análise estatística intragrupos foi encontrada significância para todos os grupos. Ocorreu significância entre os grupos C3 e F3, C3 e U3, entre C7, F3 e F7, e também entre o $\mathrm{C} 7$ e os grupos U3 e U7.

Na Figura 6 são observados os valores para a área do colágeno tipo I, observa-se que no séti- mo dia todos os grupos apresentaram maior área na reposição do colágeno. Nota-se que o grupo tratado com o fármaco tópico obteve uma diferença entre o grupo controle positivo e grupo tratado com extrato de Uvarana. O grupo tratado com o extrato de Uvarana obteve média para área de $30.90 \pm 19.90$ em relação ao grupo controle positivo que foi de $22.43 \pm 19.04$. Na análise estatística, a amostra estudada obteve valor de $\mathrm{p}=0.0001$, e significância no pós teste de Tukey's entre os grupos C3xF7, C7xF7, F3xF7, F7xU3 e F7xU7.

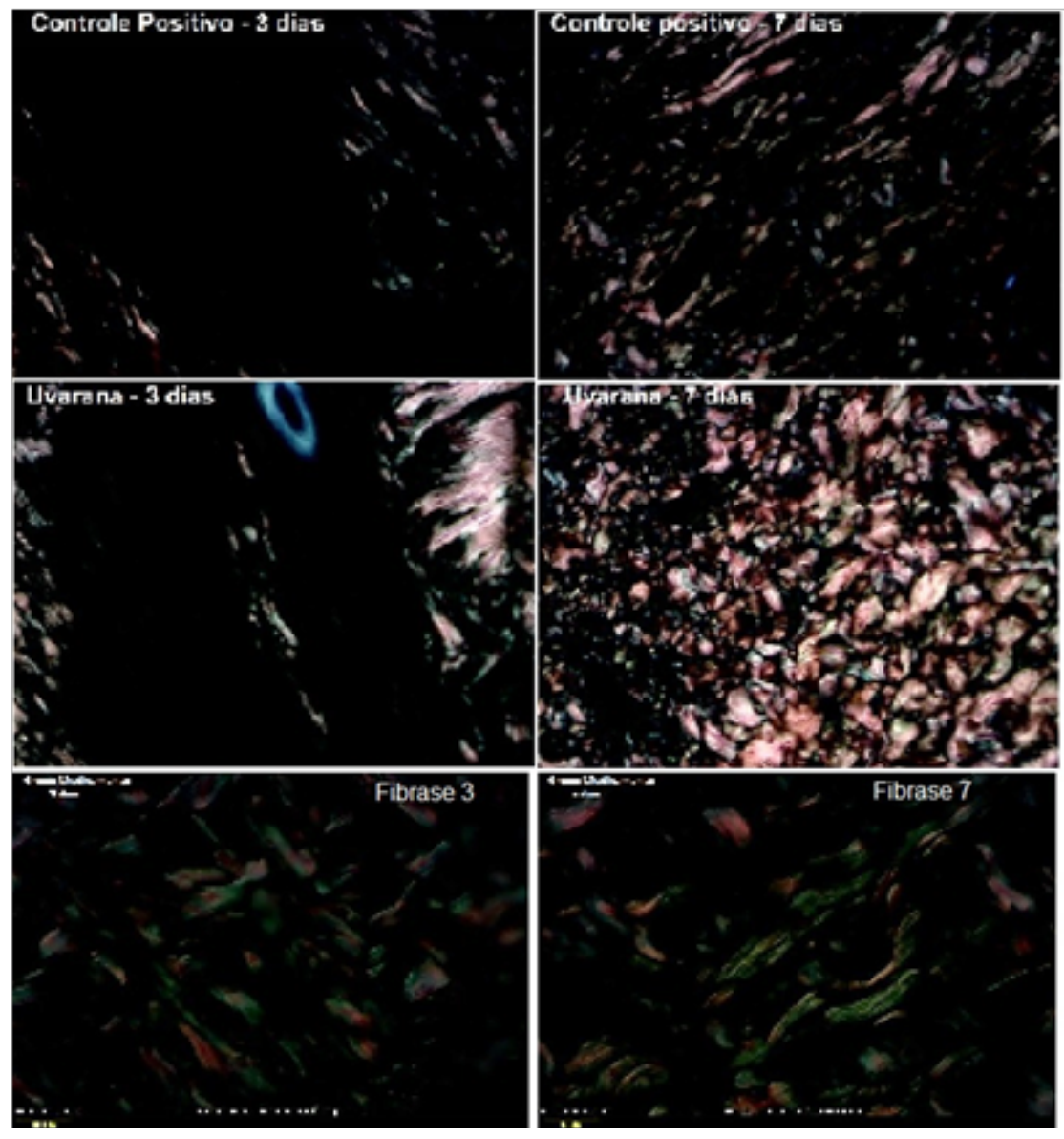

Figura 6: Presença de colágeno tipo I nos grupos tratados entre terceiro dia e sétimo dia. Lâminas coradas com Picrus sirius RED e fotografadas com luz polarizada.

\section{DISCUSSÃO}

O processo de reparo ou cicatrização de feridas é muito complexo. A remodelação tecidual da matriz extracelular é um processo dinâmico e essencial na cicatrização associada a respostas fisioló- gicas e patológicas. Esse processo consiste em uma coordenada sequência de acontecimentos celulares e bioquímicos que são responsáveis pela reconstituição do tecido, segundo o estudo de $\mathrm{Campos}^{33}$.

O emprego de plantas medicinais é bastante eficiente para acelerar a cicatrização de feridas. 
$\mathrm{Nitz}^{2}$, em seu experimento com Coronopus didymus e Calendula officinalis para tratar feridas cutâneas em ratos, relatam que o uso dessas plantas como tratamento foi responsável pela melhora e aceleração do processo cicatricial, uma vez que promoveu um aumento estatisticamente significante do número de fibroblastos e fibras colágenas. Nesse contexto, a utilização de plantas com fins medicinais se torna uma alternativa promissora e, por isso, a Uvarana foi alvo do presente estudo.

Nesse experimento utilizou-se a raiz da planta, seca e moída, conforme uso popular na região de Pitanga, Paraná. Descrito por populares, a ação da raiz apresenta efeito anti-inflamatório, analgésico e cicatrizante, auxiliando na cura de feridas.

A partir do estudo realizado por Isaac ${ }^{34}$, conclui-se que os macrófagos são células importantíssimas no processo de resposta imunológica, uma vez que eles são responsáveis por produzir diferentes citocinas que auxiliam no processo de cicatrização, um dos efeitos dessas citocinas é a quimiotaxia.

No estudo proposto foi observada a presença de macrófagos em todos os grupos no terceiro dia e, de acordo com o estudo de Isaac, o extrato aquoso de Uvarana propicia a interação quimiotáxica, a qual foi demonstrada ao sétimo dia, onde o número de células do sistema imunológico (macrófagos) diminuiu consideravelmente, o que pode estar associado às reações do oxigênio, como diminuição do estresse oxidativo.

Estudo realizado por Beltrame ${ }^{35}$, relata que o extrato bruto da Cordilyne Dracaenoides (Uvarana) reduz a produção de Óxido Nítrico (NO) na avaliação bioquímica e microbiológica.

No presente estudo observa-se a ação de redução do processo de produção do NO, pela diminuição de células mononucleares e pela reposição de colágeno tipo I ao sétimo dia quando comparado com o fármaco utilizado no estudo.

Csupor $^{36}$ relatam que em alguns casos, o uso de plantas medicinais tem um impacto direto na cicatrização e, com efeito, também na atividade anti-inflamatória. Também relatam que com a redução da inflamação, encurta-se o período inflamatório, sendo assim, remédios de ervas com um efeito anti-inflamatório tópico podem acelerar a cicatrização de feridas.
Este fato mencionado por Csupor ${ }^{36}$ corrobora com os achados no estudo proposto, onde foi observado a redução do processo inflamatório e a deposição de colágeno tanto o tipo III quanto o tipo I.

A aceleração no processo de cicatrização de feridas, atividade de certas plantas que contêm polissacarídeos foi clinicamente confirmada, e presume-se que esta atividade está fortemente relacionada com a influência sobre o sistema imunológico. Nesse contexto, é comum o uso de raízes e folhas que têm o potencial de ação cicatrizante como forma de tratamento para feridas.

Conforme estudo de Beltrame ${ }^{35}$, a Cordilyne Dracaenoides Kunth apresenta na sua composição terpenos e esteroides, bem como agentes fenólicos, tais princípios ativos resultam em diversas atividades que possuem capacidade de facilitar e acelerar o processo cicatricial em tecidos lesionados.

\section{CONCLUSÃO}

Pode-se concluir que o extrato aquoso de Cordilyne Dracaenoides Kunth apresenta relevante significância e eficácia no tratamento de lesões e pode ser utilizado como recurso terapêutico com finalidade de promover a reconstituição de tecidos lesionados.

\section{REFERÊNCIAS}

1. Blanes, L. Tratamento de feridas. Baptista-Silva JCC, editor. Cirurgia vascular: guia ilustrado. 2004. São Paulo. Disponível em: URL: http://www.bapbaptista.com

2. Nitz AC. Estudo morfométrico na cicatrização de feridas cutâneas em ratos, utilizando Coronopus didymus e Calendula officinalis. Florianópolis. [Dissertação (mestrado)] - Universidade Federal de Santa Catarina; 2005.

3. Garros IC, Campos ACL, Tâmbara EM, Tenório SB, Torres JM, Agulham MA, et al. Extrato de Passiflora edulis na cicatrização de feridas cutâneas abertas em ratos: Estudo morfológico e Histológico. Rev Acta Cirúrgica Brasileira. 2006;21(3):55-65.

4. Peterson LJ, Ellis E, Hupp JR, et al. Cirurgia oral e maxilofacial contemporânea. Rio de Janeiro: Guanabara koogan; 2000.

5. Rocha JCT. Terapia laser, cicatrização tecidual e angiogênese. Rev Bras Prom Saúde. 2004;17:44-8. 
6. Slemp AE, Kirschner RE. Keloids and scars: a review of keloids and scars, their pathogenesis, risk factors, and management. Curr Opin Pediatr. 2006;18(4):396-402

7. Durani P, Occleston N, O'kane S, Ferguson MW. Avotermin: a novel antiscarring agent. Int J Low Extrem Wounds. $2008 ; 7(3): 160-8$.

8. Gangemi EN, Gregori D, Berchialla P, Zingarelli E, Cairo M, Bollero D, et al. Epidemiology and risk factors for pathologic scarring after burn wounds. Arch Facial Plast Surg. 2008;10(2):93-102.

9. Ghahary A, Ghaffari A. Role of keratinocyte-fibroblast cross-talkind evelopment of hypertrophic scar. Wound Repair Regen. 2007;15(Suppl 1):S46-53 . Erratum in Wound Repair Regen. 2008;16(4):582.

10. Verrecchia F, Mauviel A. Transforming growth factor- beta and fibrosis .World J Gastroenterol. 2007;13(22):3056-62.

11. Armour A, Scott PG, Tredget EE. Cellular and molecular pathology of HTS: basis for treatment. Wound Repair Regen. 2007;15(Suppl1):S6-17. Erratum in Wound Repair Regen. 2008;16(4):582.

12. Clark Raf. Overview and general considerations of wound repair. In: The molecular and cellular biology of wound repair. New York: Plenum, 1p.3-33.

13. Breathnack SM, Mcgrath JA. Wound healing. In: Burns T, Breathnach S ,Cox N, Griffiths C, editors . Rook's textbook of dermatology. 7th ed. Oxford: Blackwell Science Ltd; p.11.1-11.25, 2004.

14. Häkkinen L, Csiszar A. Hereditary gingival fibromatosis: characteristicsand novel putative pathogenicmechanisms. J Dent Res. 2007;86(1):25-34.

15. Maciel, MAM, et al. Plantas medicinais: a necessidade de estudos multidisciplinares. Quím Nova. 2002;25(3):429-38.

16. Capella SO, Tillmann MT, Félix AOC, Fontoura EG, Fernandes CG, Freitag RA, et al. Potencial cicatricial da Bixa orellana L. em feridas cutâneas: estudo em modelo experimental. Arq Bras Med Vet Zootec. 2016;68(1):104-12.

17. Faleiro CC, Elias STH, Cavalcanti LC, Cavalcanti ASSI. O extrato das folhas de babosa, Aloe vera na cicatrização de feridas experimentais em pele de ratos, num ensaio controlado por placebo. Vila Velha. [Trabalho de Conclusão de Curso] - Universidade Vila Velha; 2009.

18. Carpanezzi AA, Tavares FR, Sousa VA. Estaquia da Uvarana (Cordyline dracaenoides Kunth). Embrapa Florestas-Comunicado Técnico (INFOTECA-E), 2002.

19. Mazza MCM. Potencial de aproveitamento medicinal de espécies do sub-bosque dos bracatingais da região de Curitiba, PR. Embrapa Florestas. Documentos, 43.

20. Souza CC, et al. Desenvolvimento e caracterização de Formulação Tópica de Extrato de Uvarana para Tratamento de Feridas. Revista Eletrônica de Farmácia. 2016;13(4):191-200.

21. Sparg SG, Light ME, Staden JV. Biological activities and distribution of plant saponins. Journal of Ethnopharmacology. 2004;94:219-43.
22. Oda K, Matsuda H, Murakami T, et al. Adjuvant and haemolytic activities of 47 saponins derived from medicinal and food plants. Biol Chem. 2000;381(1):67-74.

23. Sindambiwe JB, Calomme M, Geerts S, Pieters $L$, Vlietinck AJ, Vanden Berghe DA. Evaluation of biological activities of triterpenoid saponins from Maesa lanceolata. J Nat Prod. 1998;61(5):585-90.

24. Sirtori CR. Aescin: Pharmacology, pharmacokinetics and therapeutic profile. Pharmacol Res. 2001;44(3):183-93.

25. Killeen GF, Madigan CA, Connolly CR, Walsh GA, Clark C, Hynes MJ, et al. Antimicrobial saponins of Yucca schidigera and the implications of their in vitro properties for their in vivo impact. J Agric Food Chem. 1998;46(8):3178-86.

26. Iorizzi M, Lanzotti V, Ranalli G, Marino S, Zollo F. Antimicrobial furostanol saponins from the seeds of Capsicum annuum L. var. acuminatum. J Agric Food Chem. 2002; 50(15):4310-6.

27. Delmas F, Di Giorgio C, Elias R, Gasquet M, Azas N, Mshvildadze $V$, et al. Antileishmanial activity of three saponins isolated from ivy, $a$ - hederin, $\beta$-hederin and hederacolchiside $A 1$, as compared to their action on mammalian cells cultured in vitro. Planta Med. $2000 ; 66(4): 343-7$.

28. Traore F, Faure R, Ollivier E, Gasquet M, Azas N, Debrauwer $L$, et al. Structure and antiprotozoal activity of triterpenoid saponins from Glinus oppositifolius. Planta Med. 2000;66:368-71.

29. González AG, Hernández JC, León F, Padrón JL, Estévez F, Quintana J, et al. Steroidal saponins from the bark of Dracaena draco and their cytotoxic activities. J Nat Prod. 2003;66(6):793-8.

30. Kinjo J, Yokomizo K, Hirakawa T, Shii Y, Nohara T, Uyeda M. Anti-herpes virus activity of fabaceous triterpenoidal saponins. Biol Pharm Bull. 2000;23(7):887-9.

31. Kanzaki T, Morisaki N, Shiina R, Saito Y. Role of transforming growth factor- $\beta$ pathway in the mechanism of wound healing by saponin from Ginseng Radix rubra. Br J Pharmacol. 1998;125(2):255-62.

32. Huong NT, Matsumoto $\mathrm{K}$, Watanabe H. The antistress effect of majonoside-R2, a major saponin component of Vietnamese ginseng: neuronal mechanisms of action. Methods Find Exp Clin Pharmacol. 1998;20(1):65-76.

33. Campos ACL, Borges-Branco A, Groth, AK. Cicatrização de feridas. $A B C D$ arq bras cir dig. 2007;20(1):51-8.

34. Isaac C, Ladeira PRS, Rêgo FMP, Aldunate JCB, Ferreira MC. Processo de cura das feridas: cicatrização fisiológica. Revista de Medicina. 2010;89(3-4):125-31.

35. Beltrame F, Kanufre CC, Rainho B, Kiatkoski E. Evaluation of biochemical and microbiological effects of Cordyline dracaenoides Kunth (Uvarana) barks. Afr J Pharm Pharmaco. 2011;5(20):2255-64.

36. Csupor D, Blazsó G, Balogh A, Hohmann J. The traditional Hungarian medicinal plant Centaurea sadleriana Janka accelerates wound healing in rats. J Ethnopharmacol. 2010;127(1):193-5. 